\title{
Altered expression of glucose metabolism associated genes in a tacrolimus-induced post-transplantation diabetes mellitus in rat model
}

\author{
LING ZHANG $^{1 *}$, YUNQIANG HE $^{2 *}$, CUNZAO WU $^{3}$, MINMIN WU $^{1}$, XUEHAI CHEN ${ }^{1}$, \\ JIAO LUO ${ }^{1}$, YONG CAI $^{3}$, PENG XIA ${ }^{3}$ and BICHENG CHEN ${ }^{1}$ \\ ${ }^{1}$ Key Laboratory of Surgery, The First Affiliated Hospital of Wenzhou Medical University, Wenzhou, Zhejiang 325000; \\ ${ }^{2}$ Department of Endocrinology and Metabolism, Jiangsu Province Hospital, The First Affiliated Hospital of \\ Nanjing Medical University, Nanjing, Jiangsu 210029; ${ }^{3}$ Department of Transplantation, \\ The First Affiliated Hospital of Wenzhou Medical University, Wenzhou, Zhejiang 325000, P.R. China
}

Received May 6, 2017; Accepted April 17, 2019

DOI: $10.3892 / \mathrm{ijmm} .2019 .4313$

\begin{abstract}
Post-transplantation diabetes mellitus (PTDM) is a known side effect in transplant recipients administered with immunosuppressant drugs, such as tacrolimus (Tac). Although injury of islet cells is considered a major reason for Tac-induced PTDM, the involvement of insulin resistance in PTDM remains unknown. In the present study, expression levels of adipocytokines, glucose metabolism associated genes and peroxisome proliferator-activated receptor (PPAR)- $\gamma$ in adipose, muscular and liver tissues from a rat model induced with Tac $(1 \mathrm{mg} / \mathrm{kg} /$ day $)$ were examined. Rats developed hyperglycemia and glucose intolerance after 10 days of Tac administration. A subgroup of diabetic rats was further treated with rosiglitazone $(4 \mathrm{mg} / \mathrm{kg})$, a PPAR- $\gamma$ activator. Adipose, muscle and liver tissues were obtained on day 15 after induction and the results demonstrated that expression levels of adipocytokines, PPAR- $\gamma$ and proteins in the insulin associated
\end{abstract}

Correspondence to: Professor Peng Xia, Department of Transplantation, The First Affiliated Hospital of Wenzhou Medical University, 2 Fuxue Lane, Wenzhou, Zhejiang 325000, P.R. China E-mail: pengxia602@163.com

Professor Bicheng Chen, Key Laboratory of Surgery, The First Affiliated Hospital of Wenzhou Medical University, 2 Fuxue Lane, Wenzhou, Zhejiang 325000, P.R. China

E-mail: bisonch@163.com

\section{"Contributed equally}

Abbreviations: $\quad$ PPAR- $\gamma$, peroxisome proliferator-activated receptor; Tac, tacrolimus; IPGTT, intraperitoneal glucose tolerance test; Rosi, rosiglitazone; HOMA-IR, homeostasis model of assessment for insulin resistance; GLUT4, glucose transporter type-4

Key words: adipocytokines, peroxisome proliferator-activated receptor- $\gamma$, post-transplant diabetes mellitus, tacrolimus signaling pathway varied in the different groups. Rosiglitazone administration significantly improved hyperglycemia, glucose intolerance and expression levels of proteins associated with insulin signaling, as well as adipocytokines expression. The results of this study demonstrated that adipocytokines and PPAR- $\gamma$ signaling may serve important roles in the pathogenesis of Tac-induced PTDM, which may provide a promising application in the treatment of PTDM in the future.

\section{Introduction}

Tacrolimus (Tac), as an important calcineurin inhibitor, is a commonly used immunosuppressive agent inhibiting immunological rejection after organ transplantation (1). However, its clinical recommended dose is associated with numerous metabolic complications, including dyslipidemia and post-transplantation diabetes mellitus (PTDM) (2). These complications are considered risk factors for cardiovascular diseases and severe diabetes-associated disorders, and are further associated with graft dysfunction and decreased quality of life in patients after organ transplantation (3). The reported cumulative incidence of these conditions varies, with $\leq 50 \%$ reported for PTDM, depending on population, diagnostic criteria, follow-up time and administration type of immunosuppressive agents (4).

Tac administration in organ transplant recipients is an independent risk factor for PTDM according to clinical statistical analysis (5-7). A previous study demonstrated that Tac inhibits insulin secretion from islet cells and promotes apoptosis through the calcineurin/nuclear factor of activated T-cells (NFAT) signaling pathway (8). Other studies have demonstrated that Tac causes reversible inhibition of insulin expression and islet cell proliferation to induce hyperglycemia in a rat model $(9,10)$. However, associated mechanisms of Tac-induced PTDM remain unclear. Most pancreas or islet cell transplant recipients are prescribed an immunosuppression regiment with Tac (11). Due to the potential side effects of Tac on islets, certain contradictions are also observed in clinical results and basic studies (12). A decreased level of insulin was 
not evident in certain early stage patients with PTDM (12). Thus, other underlying mechanisms may be involved in this process.

The serum adiponectin concentration of pretransplant patients has been considered as an independent predictive factor for PTDM developed in clinical kidney transplantation (13). Although Tac and cyclosporine A (CSA) are similar in terms of their mechanisms of action, the level of post-transplant serum adiponectin in patients administrated with Tac is lower than in patients treated with CSA (14). Adiponectin as a major adipocyte-secreted protein has been studied in human and animal models for its improved insulin-sensitizing effects (15). The peroxisome proliferator-activated receptor (PPAR)- $\gamma$ agonist rosiglitazone has been deemed as an effective and safe treatment for patients with PTDM (16). However, to the best of our knowledge there is no evidence that the occurrence of PTDM is associated with PPAR- $\gamma$ downregulation or insulin resistance. Therefore, the current study hypothesized that Tac may modify the expression of adipocytokines and molecules in the PPAR- $\gamma$ signaling pathway, which causes insulin resistance and ultimately results in PTDM.

To verify this, a Tac-induced hyperglycemia rat model was assessed by fasting blood glucose (FBG) measurement and intraperitoneal glucose tolerance tests (IPGTTs). Expression levels of genes associated with insulin resistance, such as adipocytokines, insulin receptor (IR) substrate (S)-1/IRS-2, glucose transporter type-4 (GLUT4) and PPAR- $\gamma$ were measured and an intervention with the PPAR- $\gamma$ agonist rosiglitazone (Rosi) was initiated to investigate the role of PPAR- $\gamma /$ Akt in the pathogenesis of PTDM. Expression levels were assessed in adipose, muscular and liver tissues. In this study, it was found Tac induced insulin resistance was closely associated with the inhibition of PPAR- $\gamma$ and altered adipocytokine expression involved in the occurrence and development of PTDM. The findings of the current study may provide a promising therapeutic target for treating PTDM in the future.

\section{Materials and methods}

Materials. Tac was purchased from Astellas Pharma, Inc. (cat. no. J20090142), chloral hydrate was purchased from Beijing Biosynthesis Biotechnology Co., Ltd. and the blood glucose meter and blood glucose test strips were from SanNuo Bio-sensing. The reverse transcription kit (cat. no. SCQ-401) and the SYBR-Green fluorescence quantization kit (SYBR-Green Realtime PCR Master mix; cat. no. QPK-201) were purchased from Toyobo Life Science, the qPCR primers were from Shanghai Haohai Biological Technology Co. Ltd.; primary antibodies for GAPDH (cat. no. ab181602), GLUT4 (cat. no. ab33780), PPAR- $\gamma$ (cat. no. ab209350), Akt (cat. no. ab179463) and anti-phosphorylated Akt (cat. no. ab81283) antibodies were from Abcam.

Preliminary study. Preliminary experiments were performed to establish the dose of Tac required to induce hyperglycemia in rats. All animals were housed at $22^{\circ} \mathrm{C}$ with $12 \mathrm{~h}$ light/dark cycles, 40-70\% relative humidity and gradient pressure difference 19.8-31.6 Pa. The airflow was $\leq 0.18 \mathrm{~m} / \mathrm{sec}$ and ammonia was $\leq 15 \mathrm{mg} / \mathrm{m}^{3}$. Animals were provided with food and water ad libitum. All experimental protocols were approved by the Management Committee for Medical Laboratory Animal Sciences at Wenzhou Medical University (approval no. wydw2014-0066). A total of 18 male Sprague-Dawley rats (8 weeks; 200-220 g) were obtained from Charles River Laboratories, Inc. and treated with Tac intraperitoneally at $0.1,1$ or $10 \mathrm{mg} / \mathrm{kg} /$ day ( $\mathrm{n}=6 /$ group) for 7 days and FBG levels were measured daily. To determine the optimal dose of Rosi for preventing Tac-induced ( $1 \mathrm{mg} / \mathrm{kg} /$ day) hyperglycemia, in a preliminary study rats were treated with varying doses of Rosi (2, 4, 8, 10 mg/kg/day; n=6/group; Sigma Aldrich; Merck $\mathrm{KGaA}$ ) for 15 days. After the study, all animals were sacrificed by cervical dislocation and death was verified by assessing corneal and pain reflex, as well as respiration.

Animal model. A total of 18 male Sprague-Dawley rats (age, 8 weeks; weight, 150-200 g) were obtained from Charles River Laboratories, Inc. and as indicated and provided with food and water ad libitum. Rats were divides into three groups: i) Control group, rats were injected with saline once a day; ii) Tac group, rats were treated with Tac in saline at $1 \mathrm{mg} / \mathrm{kg} /$ day; and iii) Tac+Rosi group, rats were treated with Tac at $1 \mathrm{mg} / \mathrm{kg} /$ day and Rosi at $4 \mathrm{mg} / \mathrm{kg} /$ day. FBG levels were measured every other day using tail blood ( 10-20 $\mu \mathrm{l})$ for 15 days. The bodyweight of rats were measured daily during the experimental process. Animals were anaesthetized with $10 \%$ chloral hydrate $(350 \mathrm{mg} / \mathrm{kg}$ of body weight), anesthesia was verified by corneal and pain reflex, as well as respiration. Visceral adipose tissue, skeletal muscle and liver tissue were collected. A final blood collection was performed via vena cava puncture $(5-10 \mathrm{ml})$. Following sampling, the anaesthetized rats were sacrificed using $\mathrm{CO}_{2}$ for $>15 \mathrm{~min}$, with a flow of $20 \%$ volume/min, followed by cervical dislocation.

IPGTT. After treatment for 14 days, an IPGTT was performed after $8 \mathrm{~h}$ fasting: Glucose ( $2 \mathrm{~g} / \mathrm{kg}$ body weight $)$ was administered via intraperitoneal injection using $40 \%(\mathrm{w} / \mathrm{v})$ glucose. Blood glucose levels were measured at various time points $(0,30,60,90$ and $120 \mathrm{~min}$ after injection). The homeostasis model of assessment (HOMA-IR) was used for evaluating insulin resistance index using the following formula: FBG (mmol/l) $x$ fasting insulin concentration (mIU/l)/22.5 (17).

Radioimmunoassay. Insulin, adiponectin, leptin, resistin, visfatin, $\mathrm{RBP} 4, \mathrm{C}$ reactive protein $(\mathrm{CRP})$ and apelin concentrations in blood samples were measured by using the radioimmunoassay as described previously (18).

Immunohistochemistry. Immunohistochemical staining was performed using the streptavidin biotin peroxidase method (19). Tissues were dehydrated using gradient ethanol $(75,85,95$ and $100 \%)$ and xylene at room temperature, and embedded in paraffin at $55^{\circ} \mathrm{C}$. Then, paraffin-embedded adipose tissues were cut into $4-\mu \mathrm{m}$ sections. After deparaffinization with xylene (30 min) and gradient ethyl alcohol $(100,95,85$ and $75 \% ; 5$ min each) at room temperature, slides were boiled in the citrate buffer ( $\mathrm{pH} \mathrm{6.0)}$ for $10 \mathrm{~min}$. The activity of endogenous peroxidases was blocked by incubation with $3 \% \mathrm{H}_{2} \mathrm{O}_{2}$ in methanol for $10 \mathrm{~min}$ at room temperature. Then, sections were washed in 0.1 M PBS and blocked with $5 \%$ goat serum (Beyotime Institute of Biotechnology) in PBS 
for $60 \mathrm{~min}$ at $37^{\circ} \mathrm{C}$. Primary antibodies (rabbit anti-PPAR- $\gamma$ and GLUT4) were applied and incubated overnight at $4^{\circ} \mathrm{C}$. Control sections were incubated with normal rabbit IgG serum (cat. no. C0265; Beyotime Institute of Biotechnology). After the incubation, slides were washed with PBS after warming for $30 \mathrm{~min}$ at $37^{\circ} \mathrm{C}$ and incubated with HRP-conjugated goat anti-rabbit secondary antibody $(1: 1,000$; cat. no. A0208; Beyotime Institute of Biotechnology) for $30 \mathrm{~min}$ at $37^{\circ} \mathrm{C}$. Diaminobenzidine reagent (1:50; OriGene Technologies, Inc.) was applied at room temperature for $1 \mathrm{~min}$ and hematoxylin solution was used to stain nucleus for $5 \mathrm{~min}$ at room temperature. Finally, sections were dehydrated and covered with resinous mounting agent (neutral resin; Beyotime Institute of Biotechnology) at room temperature and immediately analyzed. For each section, $>6$ fields were evaluated by light microscopy and all measurements were performed on blinded slides (magnification, $\mathrm{x} 400$ ). The intensity of positive staining was measured using the IOD/area (Image-Pro Plus 6.0; Media Cybernetics, Inc.).

Western blot. Total protein was extracted from he tissues using RIPA lysis buffer and the concentration was determined by BCA protein assay (Beyotime Institute of Biotechnology). A total of $50 \mu \mathrm{g}$ protein was separated using $10 \%$ SDS-PAGE gels and transferred to polyvinylidene fluoride membranes. Membranes were blocked with 5\% nonfat milk in TBS for $2 \mathrm{~h}$ at room temperature and incubated overnight at $4^{\circ} \mathrm{C}$ with primary antibodies (anti-PPAR- $\gamma$, anti-p-Akt, anti-Akt, anti-GLUT4 and anti-GAPDH) at 1:1,000 dilution. Membranes were washed with TBST and incubated with HRP-conjugated IgG goat anti-rabbit secondary antibody (cat. no. ab7090; Abcam) at 1:5,000 dilution for $2 \mathrm{~h}$ at room temperature. The immune complex was visualized using an ECL Western Blotting Detection system (Amersham; GE Healthcare) and intensities were quantified using Quantity One software (V4.6.6; Bio-Rad Laboratories, Inc.).

$R T-q P C R$. Total RNA was extracted from adipose, muscle and liver tissues using TRIzol ${ }^{\circledR}$ reagent. cDNA was prepared using the PrimeScript TMRT Master mix (Takara Bio, Inc.). qPCR was performed in three reduplicative samples using SYBR-Green reagent (Takara Bio, Inc.). The primer sequences were as follows: PPAR- $\gamma$, forward, 5'-GGACCTCTCTGT GATGGATGA-3' and reverse, 5'-GCTCTTGTGAACGGGA TGT-3', fragment length, $114 \mathrm{bp}$; adiponectin, forward, 5'-CCT CCACCCAAGGAAACTT-3' and reverse, 5'-ACCAAGAAC ACCTGCGTCTC-3', fragment length, 13 bp; leptin, forward, 5'-CCTGTGGCTTTGGTCCTATC-3' and reverse, 5'-ATA CCGACTGCGTGTGTGAA-3', fragment length, 128 bp; resistin, forward, 5'-GCCAGTGCGGAAGCATAGACT-3' and reverse, 5'-GTATTTCCAGACCCTCATCTCGTTT-3', fragment length, $189 \mathrm{bp}$; visfatin, forward, 5'-AGCGGCAGA GCACAGTAACCTAT-3' and reverse, 5'-CCACAGACACAG GCACTGATGA-3', fragment length, 186 bp; retinal binding protein 4 (RBP4), forward, 5'-TGGTATGCCATCGCC AAA-3' and reverse, 5'-TCCCAGTTGCTCAGAAGACG-3', fragment length, 134 bp; GLUT4, forward, 5'-CCTGCTTGG CTTCTTCATCT-3' and reverse, 5'-GGGTTTCACCTCCTG CTCTA-3', fragment length, $121 \mathrm{bp}$; IR, forward, 5'-GCTCCT ATGCTCTGGTGTCA-3' and reverse, 5'-TCGTGAGGTTGT
GCTTGTTC-3', fragment length, 147 bp; IRS-1 for adipocyte and muscle, forward, 5'-CAGGCACCATCTCAACAATC-3' and reverse, 5'-GTTTCCCACCCACCATACTG-3', fragment length, 107 bp; IRS-2 for liver, forward, 5'-GTTTCCCACCCA CCATACTG-3' and reverse, 5'-TACTTGCGGTGGTGGA GAC-3', fragment length, $150 \mathrm{bp}$; IL-6, forward, 5'-TCCTTA GCCACTCCTTCTGT-3' and reverse, 5'-CTCATTCTGTCT CGAGCCCACCA-3'; TNF- $\alpha$, forward, 5'-CATGGATCTCAA AGACAACCAA-3' and reverse, 5'-CTCCTGGTATGAAAT GGCAAAT-3'. The reaction conditions were as follows: $95^{\circ} \mathrm{C}$ for $3 \mathrm{~min}$, followed by 40 cycles of $95^{\circ} \mathrm{C}$ for $5 \mathrm{sec}$ and $62^{\circ} \mathrm{C}$ for $35 \mathrm{sec}$. The data was analyzed using the $2^{-\Delta \Delta \mathrm{Cq}}$ method (20).

Statistical analysis. Data are presented as the mean \pm standard deviation. Unpaired Student's t-test was used to compare the differences between two groups. Multiple comparisons were performed using a one-way ANOVA with Bonferroni correction. $\mathrm{P}<0.05$ was considered to indicate a statistically significant difference. All analyses were performed using SPSS (20.0; IBM Corp.).

\section{Results}

Preliminary study. Preliminary experiments were performed to establish the dose of Tac required to induce hyperglycemia in rats. After intraperitoneal administration with Tac at $0.1,1$ and $10 \mathrm{mg} / \mathrm{kg} /$ day for 7 days, it was found that Tac at $1 \mathrm{mg} / \mathrm{kg} /$ day achieved the best results. To determine the optimal dose of Rosi for preventing Tac-induced hyperglycemia, varying doses of Rosi (2, 4, 8 and $10 \mathrm{mg} / \mathrm{kg} / \mathrm{day})$ were trialed in this study. It was determined that $4 \mathrm{mg} / \mathrm{kg}$ Rosi combined with ad libitum fed did not result in hypoglycemia. This dose $(4 \mathrm{mg} / \mathrm{kg})$ was further effective in improving insulin resistance in the rats treated with Tac.

Measurements of body weight, FBG and insulin tolerance. Rats were treated with Tac by intraperitoneal injection for 14 days ( $1 \mathrm{mg} / \mathrm{kg} /$ day) in the presence or absence of Rosi ( $4 \mathrm{mg} / \mathrm{kg} /$ day). As shown in Fig. 1A, the body weight of the rats increased in all groups over the duration of the study and no significant differences were observed. Additionally, over the first 10 days, no significant differences in FBG levels were determined for rats of the different groups (Fig. 1B). After 10 days, rats treated with Tac presented hyperglycemia (FBG, >6.9 mmol/l) for the last 5 days of this study, while rats in the Tac+Rosi and the control group stayed within the normal range. After treatment for 14 days, the blood glucose concentration was significantly increased in the Tac group $(7.73 \pm 0.73 \mathrm{mmol} / \mathrm{l})$ when compared with the control $(5.8 \pm 0.10 \mathrm{mmol} / \mathrm{l} ; \mathrm{P}<0.01)$ and the Tac+Rosi group $(6.30 \pm 0.36 \mathrm{mmol} / \mathrm{l} ; \mathrm{P}<0.05)$. The blood glucose levels in the control and the Tac+Rosi group were not significantly different.

Rats were subjected to an IPGTT after fasting for $8 \mathrm{~h}$ at day 14 and the blood glucose concentration was measured using tail vein blood in $30 \mathrm{~min}$ intervals over $120 \mathrm{~min}$. As shown in Fig. 1C, blood glucose levels in the Tac group were significantly higher than in the Tac+Rosi and control group for the duration of the experiment. No significant differences were observed between the Tac+Rosi and the control group $(\mathrm{P}>0.05)$. The HOMA-IR was measured using the 

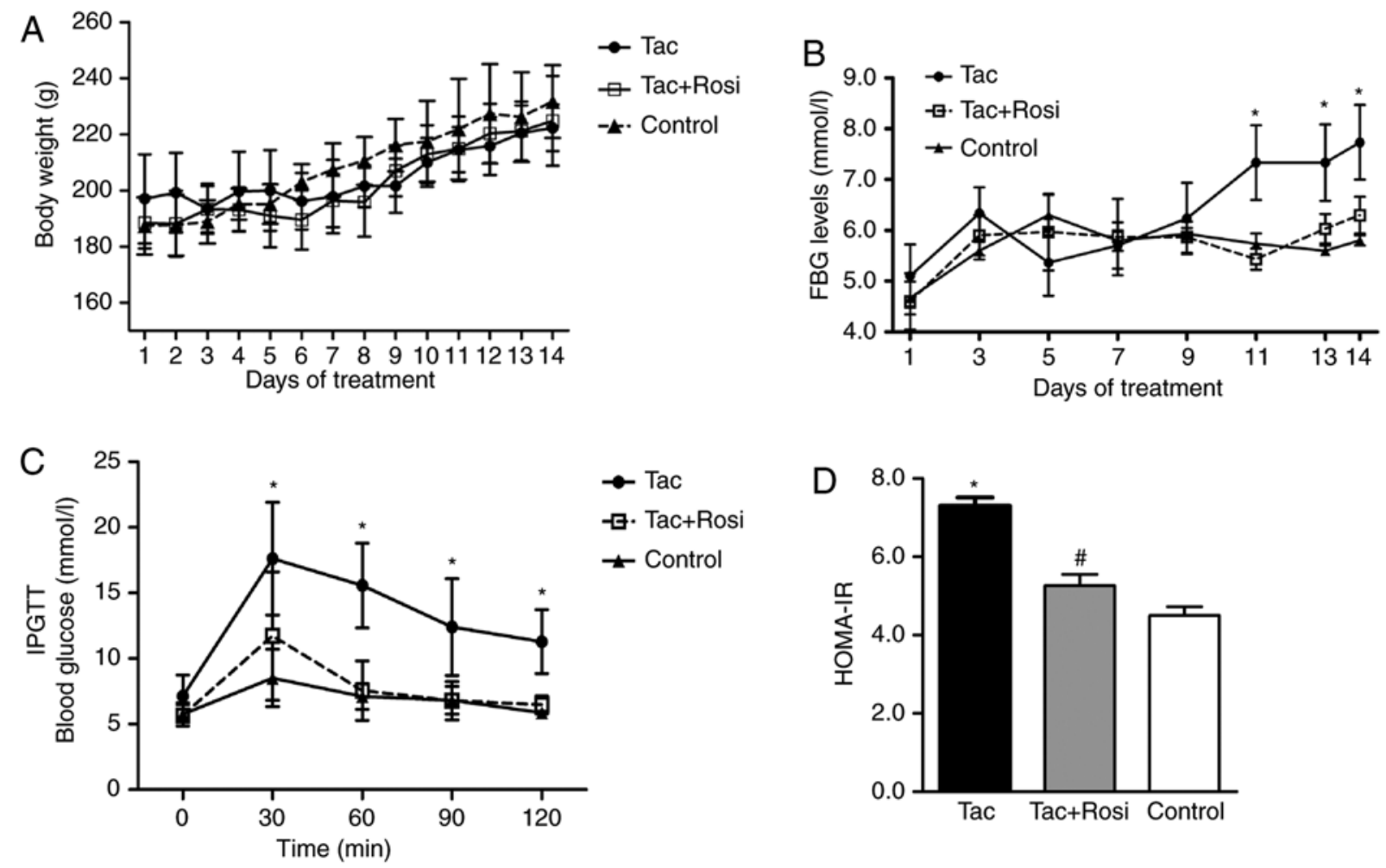

Figure 1. Body weight, FBG and IPGTT over the experimental period. Rats were treated with Tac or Tac+Rosi for 2 weeks; saline-treated rats were used as controls. (A) Body weight of rats determined daily. (B) FBG levels measured every other day. (C) On day 15 after fasting for 8 h, IPGTT was performed and blood glucose levels were measured every $30 \mathrm{~min}$ for $120 \mathrm{~min}$. (D) HOMA-IR calculated as follows: Fasting insulin level (1 $\mu \mathrm{U} / \mathrm{ml}) \mathrm{x}$ fasting glucose $(\mathrm{mmol} / \mathrm{l}) / 22.5$. Data are presented as the mean \pm standard deviation. ${ }^{~} \mathrm{P}<0.05$ vs. control; ${ }^{*} \mathrm{P}<0.05$ vs. Tac. IPGTT, intraperitoneal glucose tolerance test; Tac, tacrolimus; Rosi, rosiglitazone; HOMA-IR, homeostasis model of assessment for insulin resistance.

aforementioned formula. The result showed that a significant insulin resistance was established in rats of the Tac group compared with the control $(\mathrm{P}<0.01)$ and the Tac+Rosi group ( $\mathrm{P}<0.05$; Fig. 1D).

Insulin and adipocytokines levels in plasma. Blood samples were obtained to measure plasma insulin and adipocytokine levels using radioimmunoassays (Table I). The concentration of insulin, adiponectin, leptin, resistin, visfatin, RBP4, CRP and apelin were measured. Compared with the Tac group, there were no significant differences in the plasma concentration of insulin and adipocytokine in the Tac+Rosi group, except for apelin which was significantly increased in the Tac+Rosi group $(\mathrm{P}<0.05)$. No significant differences in insulin, adiponectin, leptin, resistin, visfatin, RBP4, CRP and apelin levels were observed between the Tac and the control group. However, apelin was significantly increased in the Tac+Rosi group when compared with the control group $(\mathrm{P}<0.05)$.

Expression of adipocytokine associated genes. Expression levels of adipocytokine-associated genes were measured by RT-qPCR in adipocytes. As shown in Fig. 2, compared with the control, mRNA levels of adiponectin and leptin were significantly decreased after treatment with Tac, and resistin, visfatin, IL-6, TNF- $\alpha$ and RBP4 were significantly increased in the Tac group. In the Tac+Rosi group, mRNA levels of adiponectin and leptin were increased, and resistin and visfatin were decreased compared with the Tac group. Furthermore, in the Tac+Rosi group expression of visfatin
( $\mathrm{P}<0.05)$, IL-6 $(\mathrm{P}<0.01)$, TNF- $\alpha(\mathrm{P}<0.01)$ and RBP4 $(\mathrm{P}<0.05)$ were significantly increased compared with the control group. Immunohistochemical staining with PPAR- $\gamma$ and GLUT4 of the adipose tissue suggested decreased expression of PPAR- $\gamma$ and GLUT4 in the Tac compared with the other two groups.

Expression of PPAR- $\gamma$ in adipocyte, muscle and liver tissues. PPAR- $\gamma$ is an important factor in the process of insulin resistance (21). In addition to adipose tissue, it has been found in skeletal muscle and liver tissues of humans and rodents $(21,22)$. In the current study, expression of PPAR- $\gamma$ was measured by RT-qPCR and western blotting. As shown in Fig. 3, protein and gene expression of PPAR- $\gamma$ were significantly decreased in the three different tissues from the Tac group compared with the control group. Compared with the control group, PPAR- $\gamma$ mRNA was decreased by 60,66 and $95 \%$ in the adipose, muscle and liver tissues of the Tac group, respectively. In the same groups, protein levels were decreased by 42,87 and $70 \%$ in the adipose, muscle and liver tissues, respectively. After administration of Rosi, the PPAR- $\gamma$ mRNA level was significantly increased compared with the Tac group.

Role of PPAR- $\gamma$ in the insulin signaling pathway. To investigate the effect of PPAR- $\gamma$ on the insulin pathway, expression of IR, IRS-1/2, activation of Akt and expression of its downstream substrate GLUT4 were detected. Akt is an important factor in the insulin signaling pathway and its phosphorylation had been considered to be associated with the biological function of insulin (23). As shown in Fig. 4, mRNA levels of IR and 
Table I. Plasma concentrations of insulin and adipocytokines in rats treated with saline, Tac or Tac+Rosi for 2 weeks.

\begin{tabular}{lrrr}
\hline Insulin and adipocytokines & Tac & Tac+Rosi & Control \\
\hline Insulin $(\mu \mathrm{IU} / \mathrm{ml})$ & $20.72 \pm 5.85$ & $25.02 \pm 6.55$ & $24.19 \pm 4.27$ \\
Adiponectin $(\mathrm{ng} / \mathrm{ml})$ & $13.13 \pm 2.32$ & $14.82 \pm 1.70$ & $14.07 \pm 1.58$ \\
Leptin $(\mathrm{ng} / \mathrm{ml})$ & $7.82 \pm 1.57$ & $8.35 \pm 1.10$ & $8.25 \pm 1.29$ \\
Resistin $(\mathrm{ng} / \mathrm{ml})$ & $19.92 \pm 1.30$ & $19.73 \pm 4.12$ & $19.46 \pm 2.78$ \\
Visfatin $(\mathrm{ng} / \mathrm{ml})$ & $56.10 \pm 6.64$ & $54.72 \pm 13.72$ & $56.91 \pm 16.52$ \\
RBP4 $(\mathrm{ng} / \mathrm{ml})$ & $40.35 \pm 6.24$ & $41.06 \pm 6.20$ & $39.24 \pm 4.80$ \\
CRP $(\mathrm{ng} / \mathrm{ml})$ & $0.95 \pm 0.02$ & $0.97 \pm 0.02$ & $0.96 \pm 0.02$ \\
Apelin $(\mathrm{ng} / \mathrm{ml})$ & $50.48 \pm 5.26$ & $55.70 \pm 5.84^{\mathrm{a}}$ & $45.53 \pm 5.79$
\end{tabular}

Data are presented as the mean \pm standard deviation. ${ }^{\text {P }}<0.05$ vs. Tac. Tac, tacrolimus; Rosi, rosiglitazone; RBP4, retinol binding protein 4 ; CRP, C reactive protein.
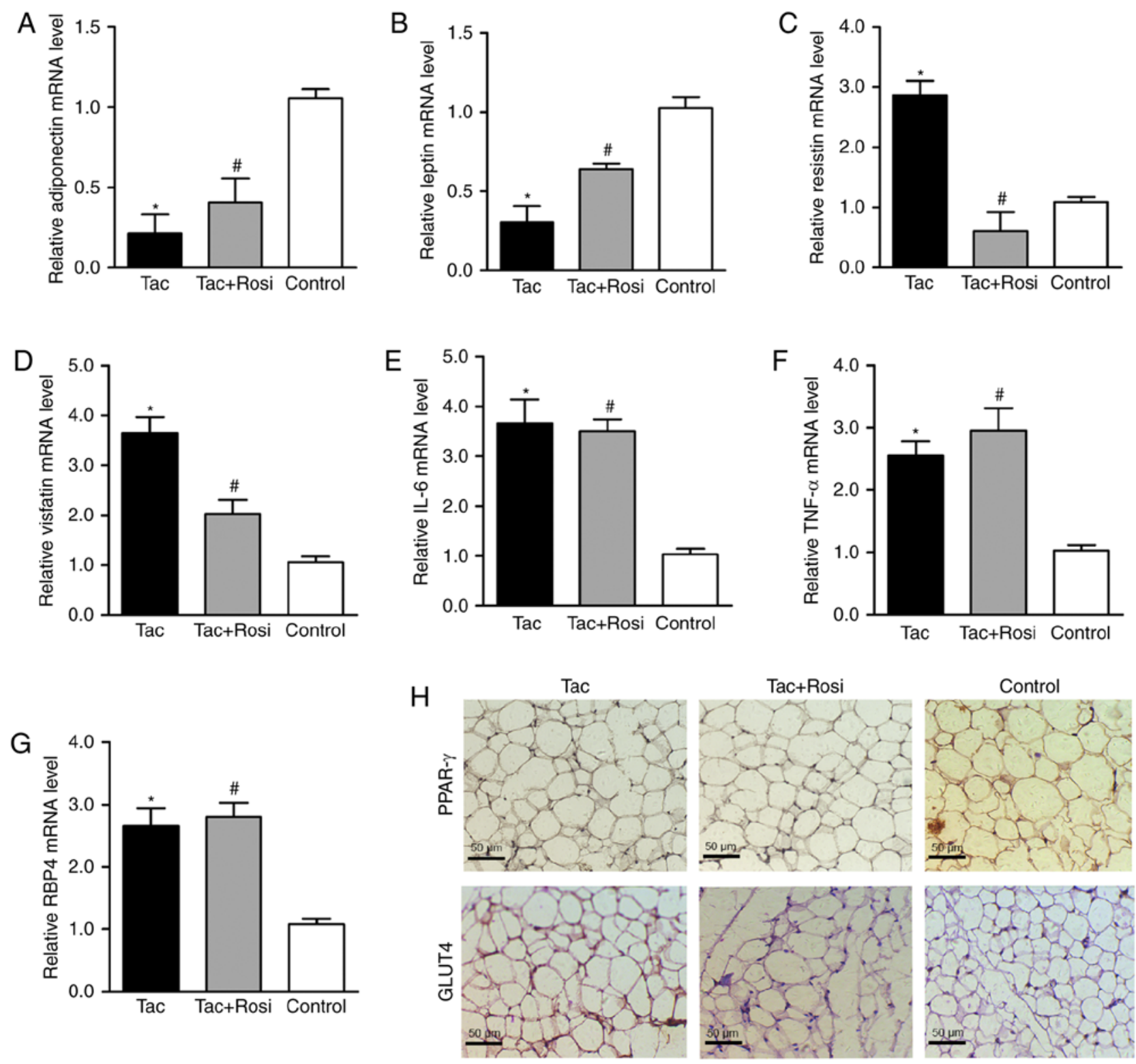

Figure 2. Effects of Tac and Tac+Rosi on the expression of adipocytokines in rat adipocytes. Rats were treated with Tac or Tac+Rosi for 2 weeks; saline-treated rats were used as controls. Relative mRNA expression of (A) adiponectin, (B) leptin, (C) resistin, (D) visfatin, (E) IL-6, (F) TNF- $\alpha$ and (G) RBP4 determined by RT-qPCR. (H) Immunohistochemical staining for PPAR- $\gamma$ and GLUT4 in adipocyte tissue (magnification, $\mathrm{x} 400$; scale bar, $50 \mu \mathrm{m}$ ). Data are presented as the mean \pm standard deviation. ${ }^{*} \mathrm{P}<0.05$ vs. control; ${ }^{\mathrm{P}} \mathrm{P}<0.05$ vs. Tac. PPAR- $\gamma$, peroxisome proliferator-activated receptor; Tac, tacrolimus; Rosi, rosiglitazone; GLUT4, glucose transporter type-4; RBP4, retinol binding protein 4. 
A
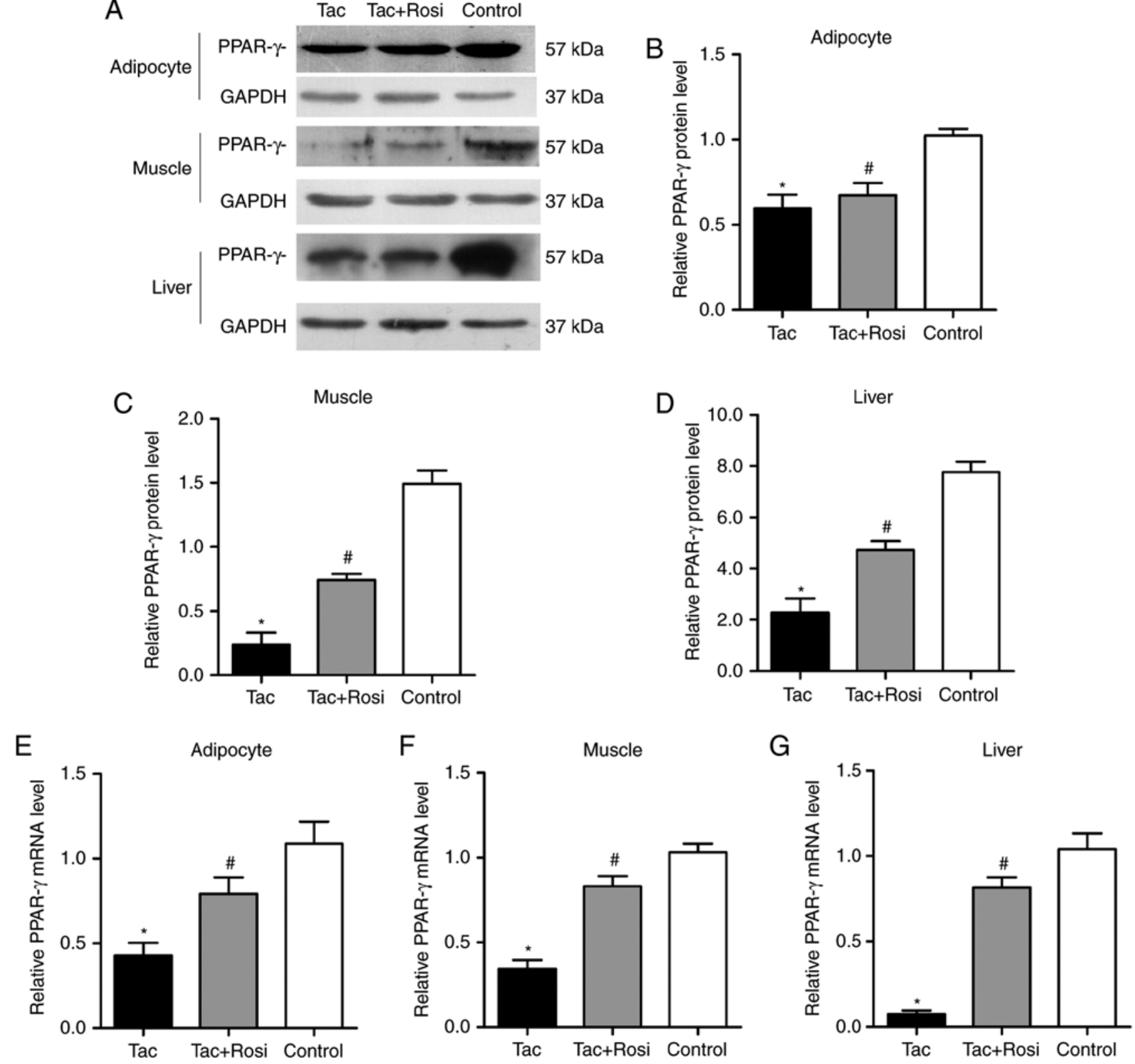

Figure 3. Effects of Tac and Tac+Rosi on the expression of PPAR- $\gamma$. Rats were treated with Tac or Tac+Rosi for 2 weeks; saline-treated rats were used as controls. PPAR- $\gamma$ expression was determined in adipocyte, muscle and liver tissues. (A) PPAR- $\gamma$ western blot images and quantification for (B) adipocyte, (C) muscle and (D) liver tissues. PPAR- $\gamma$ mRNA levels (F) in (E) adipocyte muscle and (G) liver tissues. Data are presented as the mean \pm standard deviation. ${ }^{*} \mathrm{P}<0.05$ vs. control; ${ }^{\#} \mathrm{P}<0.05$ vs. Tac. PPAR- $\gamma$, peroxisome proliferator-activated receptor; Tac, tacrolimus; Rosi, rosiglitazone.

IRS-1/2 were significantly decreased in all tissues after Tac treatment compared with the control. However, GLUT4 levels were significantly decreased compared with the control in the adipocyte and muscle tissues and significantly increased in the liver samples. Furthermore, GLUT4 expression in adipocytes $(\mathrm{P}<0.05)$ and muscle $(\mathrm{P}<0.05)$ was significantly increased in the Tac+Rosi group compared with the Tac group. RT-qPCR results were consistent with the western blotting analysis (Fig. 5).

Akt activation was evaluated in this study (Fig. 5C and D). Compared with the control group, the level of phosphorylation was significantly decreased by 61,73 and $86 \%$ in the adipose, muscle or liver tissues of the Tac group, respectively. Phosphorylation was significantly increased in all tissues after Rosi treatment compared with the Tac group. Interestingly, the increase in phosphorylation differed between tissues and in the adipocyte tissue a higher value was observed in the Tac+Rosi group compared with the control.

\section{Discussion}

Tac is one of the most frequently used immunosuppressants in the treatment of transplantation recipients (24). PTDM is considered an important side effect of Tac treatment (25). There are several studies where animal models have shown that different doses of Tac cause PTDM after organ or cell transplantation $(26,27)$; however, most recent studies focused on islet cell injury $(8,28)$. Peripheral tissue is a vital location of the glucose metabolism (29). Altered expression of glucose metabolism associated genes in the insulin signaling pathway 
A

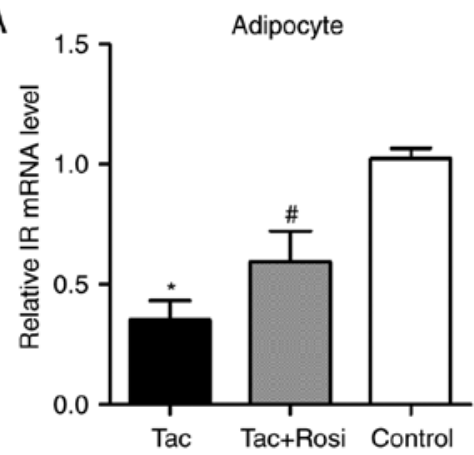

B
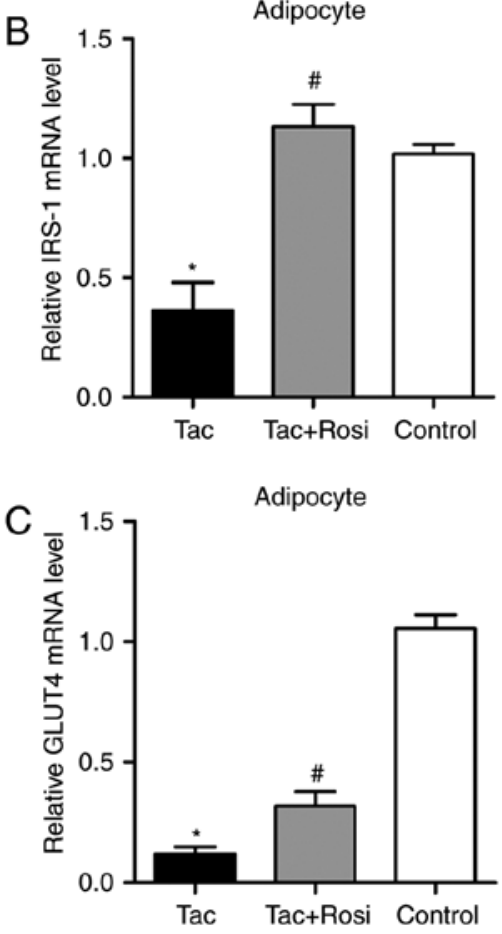
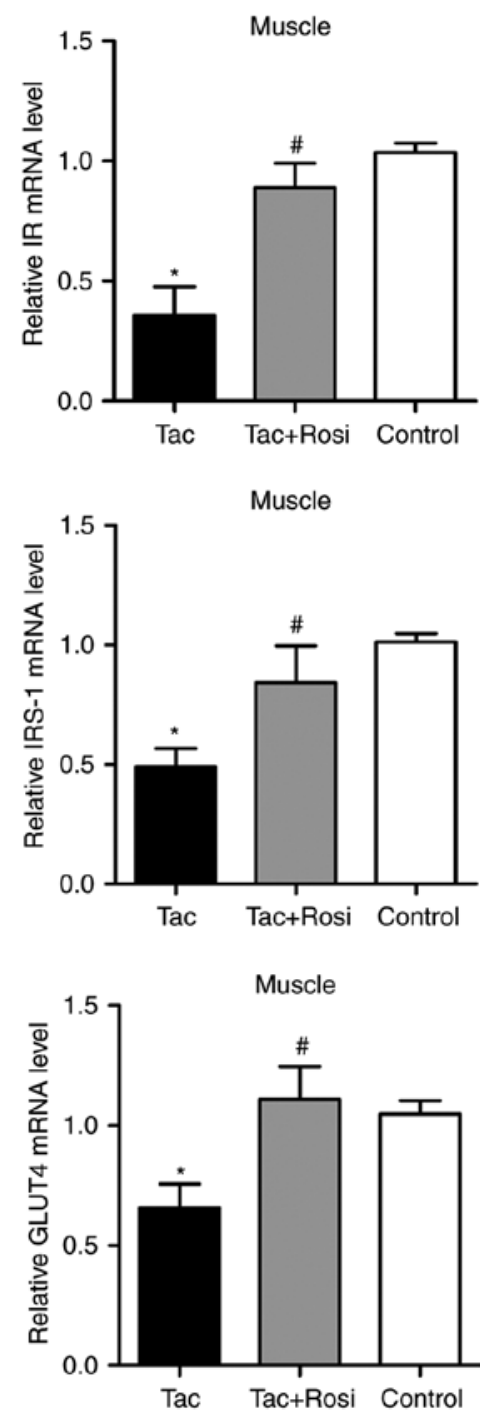
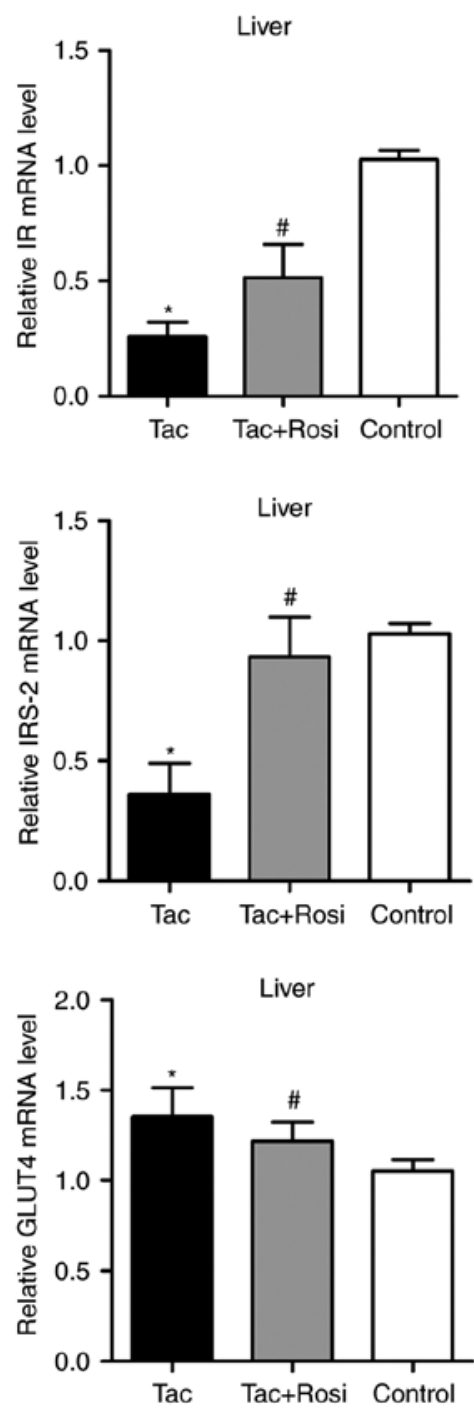

Figure 4. IR, IRS-1/2 and GLUT4 mRNA levels in adipocyte, muscle and liver tissues. Rats were treated with Tac or Tac+Rosi for 2 weeks; saline-treated rats were used as controls. mRNA levels were determined in adipocyte, muscle and liver tissues using RT-qPCR. (A) Relative mRNA expression of IR. (B) Relative mRNA expression of IRS-1 in adipocyte and muscle tissues and IRS-2 expression in liver tissues. (C) Relative mRNA expression of GLUT4. Data are presented as the mean \pm standard deviation. ${ }^{*} \mathrm{P}<0.05$ vs. control; ${ }^{*} \mathrm{P}<0.05$ vs. Tac. Tac, tacrolimus; Rosi, rosiglitazone; GLUT4, glucose transporter type- 4 ; IR, insulin receptor, IRS, IR substrate.

may be associated with Tac induced PTDM. Therefore, in the present study, an in vivo model was used to mimic immunosuppressant therapy following organ transplantation. A diabetic state was found after prolonged treatment of the rats with Tac and hyperglycemia occurred after 10 days of Tac administration. However, rats treated with Tac+Rosi stayed euglycemic.

Clinical studies have reported that insulin resistance and $\beta$-cell dysfunction serve significant roles during the process and pathogenesis of PTDM (30). The present study showed that glucose tolerance in rats treated with Tac was impaired and the HOMA-IR was increased compared with the control rats. This demonstrated that insulin resistance may occur earlier than insulin deficiency. PPAR- $\gamma$ plays a significant role in type 2 diabetes mellitus by regulating the secretion of adipocytokines through PPAR- $\gamma$-mediated signaling pathways $(31,32)$. Adipocytokines increase the sensitivity to glucose and reduce insulin resistance, which reverse glucose intolerance as reported in previous clinical studies $(33,34)$. Some studies found that Rosi treatment is a safe option for patients with PTDM after kidney transplantations (35). In this study, it was found that Rosi increased expression of proteins of the insulin signaling pathway and reduced insulin resistance. These observations were consistent with the altered expression of PPAR- $\gamma$ reported previously (36). The results of the current study demonstrated that the effect of Rosi was PPAR- $\gamma$-dependent and suggested that the PPAR- $\gamma$ agonist ameliorated the inhibition of Tac to PPAR- $\gamma$. PPAR- $\gamma$ and Tac may be promising therapeutic targets for PTDM in the future.

Further experiments were performed to determine PPAR- $\gamma$ expression and the secretion levels of adipocytokines, including adiponectin, IL- 6 , TNF- $\alpha$, leptin, resistin, visfatin and RBP4 in adipocyte. IL- 6 and TNF- $\alpha$ are considered closely associated with adiposity and insulin resistance and are highly expressed in adipose tissues $(37,38)$. In the present study, except for impaired glucose tolerance, it was observed that expression of adiponectin and leptin were significantly reduced in the Tac group accompanied by increased expression of resistin, visfatin and RBP4 compared with the control 

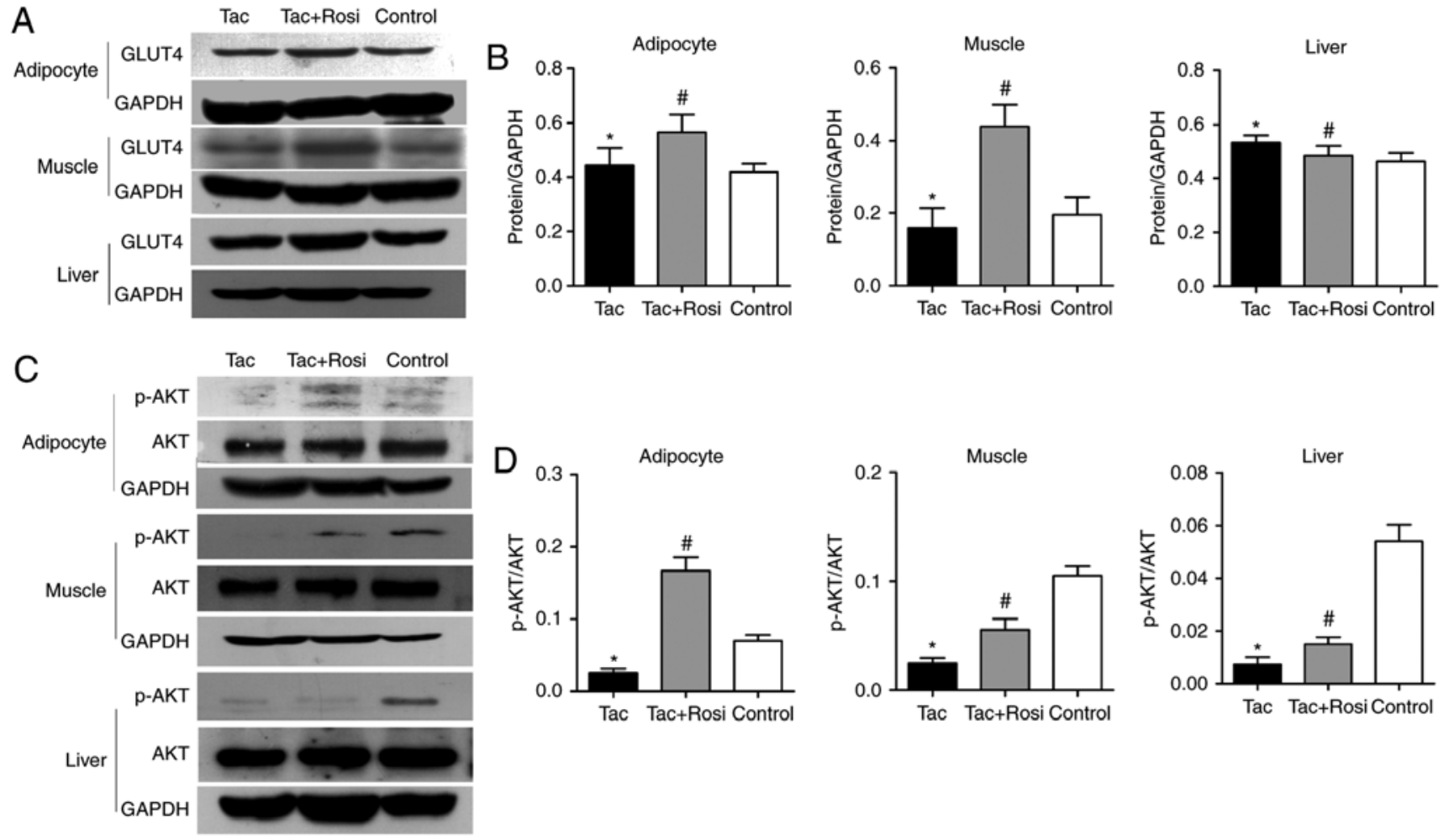

Figure 5. Effects of Tac and Tac+Rosi on GLUT4 protein expression and activation of Akt. Rats were treated with Tac or Tac+Rosi for 2 weeks; saline-treated rats were used as controls. Protein levels were determined in adipocyte, muscle and liver tissues by western blotting. (A) Membrane images and (B) quantification of GLUT4 protein expression. (C) Membrane images and (D) quantification of Akt and p-Akt levels. Data are presented as the mean \pm standard deviation. ${ }^{\text {"P }}<0.05$ vs. control; ${ }^{~} \mathrm{P}<0.05$ vs. Tac. Tac, tacrolimus; Rosi, rosiglitazone; GLUT4, glucose transporter type-4; p-, phosphorylated.

Plasma concentrations of insulin and adipocytokines were also measured. The level of insulin was increased in the Tac+Rosi group compared with the Tac group, which may be caused by a stress response. It is well known that PPAR- $\gamma$ agonists like Rosi promote the secretion of adiponectin and leptin by stimulating the expression of PPAR- $\gamma$ in the patients with diabetes mellitus (39). It was concluded that PPAR- $\gamma$ and adipocytokines may serve an important role in the induction of diabetes after treatment with Tac.

Insulin resistance describes the need for increased insulin to achieve biological effects (40). The insulin signaling pathway is composed of various molecules and proteins which initiate IR tyrosine kinase activation and substrate phosphorylation (41). However, it is not known whether this pathway is affected by the altered expression of proteins and molecules, and the activation of enzymes and transcription factors in peripheral tissue induced by Tac. IRS-1 is primarily observed in adipocyte and muscle tissues and plays a critical role in process of glucose metabolism $(42,43)$. IRS-2 is primarily observed in the liver and participates in the process of maintaining glucokinase activity (44). In this study, mRNA expression of IR, IRS-1/2 and GLUT4 were inhibited by Tac in various peripheral tissues and the phosphorylation of Akt was altered compared with the control. Rosi treatment further affected the expression levels of these factors.

The effect of Tac in blocking immunoreaction is via inhibition of calcineurin through the calcineurin/NFAT signaling pathway. It was hypothesized that there may be an interaction between calcineurin/NFAT and PPAR- $\gamma$ in adipocytes, hepatocytes and myocytes (45). Consistent with this, the calcineurin inhibitor Tac was applied and PPAR- $\gamma$ expression was evaluated. It suggested that there may be an association between calcineurin/NFAT and PPAR- $\gamma$ in different peripheral tissues. Tac has been reported to inhibit calcineurin activity and downregulate the nuclear localization potentially affected by PPAR- $\gamma$ gene activation and decreased expression levels of PPAR- $\gamma$ and adiponectin (46). Adiponectin is one of the most important adipocytokines to control the glucose metabolism and insulin sensitivity, exerting insulin-sensitizing effects through binding to specific receptors, leading to AMPK and PPAR- $\alpha$ activation (47). It suppresses gluconeogenic gene expression and its dysfunction has been implicated in insulin resistance, diabetes and cardiovascular diseases.

It was found that the degree of decreased expression of PPAR- $\gamma$ varied among the three different tissues. Thus, a future study may be designed using different types of cells, such as adipocytes, muscle and liver cells. The preliminary results obtained in this study provided a base for follow-up experiments and the knockdown or inhibition of the PPAR- $\gamma$ signaling pathway may be studied to investigate whether the degree of insulin resistance is associated with varied expression of PPAR- $\gamma$ in multiple cell lines. There were various limitations associated with the current study. Since the occurrence of PTDM has been closely associated with many factors in clinical and experimental studies (48), the aim of the present study was to evaluate the effects of an immunosuppressant in the pathogenesis of PTDM and an animal model was established using Tac. However, PTDM animal models that follow kidney or other solid organ transplantation require 
to be evaluated in the future. Furthermore, the current study only measured a small selection of molecules from the insulin signaling pathway in the glucose metabolism, and the plasma adipocytokine and insulin-derived index levels have not been fully validated in rodents and require to be further investigated. The time point chosen to determine drug effect may have been too short in this study and future evaluation may include multiple response times.

In summary, the mechanisms responsible for the occurrence of glucose intolerance induced by Tac may be attributed to an increased insulin resistance in various peripheral tissues, in addition the previously reported islet cell injury and impairment of islet cell secretion (49). According to the results presented in the current study, Tac induced insulin resistance may be closely associated with the inhibition of PPAR- $\gamma$ and altered adipocytokine expression involved in the occurrence and development of PTDM. These findings may provide a promising therapeutic target to prevent PTDM caused by Tac in future.

\section{Acknowledgements}

Not applicable.

\section{Funding}

This project was supported by the Municipal Science and Technology Bureau of Wenzhou (grant no. Y20140672) and the Public Welfare Project of Science and Technology Department of Zhejiang Province (grant no. 2015C33186).

\section{Availability of data and materials}

All data generated or analyzed during this study are included in this published article.

\section{Authors' contributions}

$\mathrm{LZ}$ and $\mathrm{YH}$ were involved in the conception, design and drafting the manuscript. $\mathrm{CW}$ and $\mathrm{MW}$ collected and assembled the data. XC and JL were involved in the data analysis and interpretation. YC was involved in data analysis, figures preparation and revised the manuscript. PX and BC participated in the conception and design of this study, provided technical support and final approval of the manuscript. All authors had full access to the data in and take responsibility for the integrity and accuracy of data analysis.

\section{Ethics approval and consent to participate}

The present study was approved by The First Affiliated Hospital of Wenzhou Medical University Ethics Committee.

\section{Patient consent for publication}

Not applicable.

\section{Competing interests}

The authors declare that they have no competing interests.

\section{References}

1. Moura Penteado LA, Lucena GM, Brandão Peixoto MO, Barbosa TC, de Souza Leitão Arruda AC and Cimões R: Evaluation of the effect of tacrolimus on periodontitis induced in rats. Arch Oral Biol 80: 89-94, 2017.

2. Chien YS, Chen YT, Chuang CH, Cheng YT, Chuang FR and Hsieh H: Incidence and risk factors of new-onset diabetes mellitus after renal transplantation. Transplant Proc 40: 2409-2411, 2008.

3. Lancia P, Adam de Beaumais T and Jacqz-Aigrain E: Pharmacogenetics of posttransplant diabetes mellitus. Pharmacogenomics J 17: 209-221, 2017.

4. Montori VM, Basu A, Erwin PJ, Velosa JA, Gabriel SE and Kudva YC: Posttransplantation diabetes: A systematic review of the literature. Diabetes Care 25: 583-592, 2002.

5. Demirci MS, Toz H, Yilmaz F, Ertilav M, Asci G, Ozkahya M, Zeytinoglu A, Nart D and Ok E: Risk factors and consequences of post-transplant diabetes mellitus. Clin Transplant 24: E170-E177, 2010.

6. Ericzon B, Groth C, Bismuth H, Calne R, McMaster P, Neuhaus P, Otto G, Pichlmayr R and Williams R: Glucose metabolism in liver transplant recipients treated with FK 506 or cyclosporin in the European multicentre study. Transplt Int 7 (Suppl 1): S11-S14, 1994.

7. Lohmann T, List C, Lamesch P, Kohlhaw K, Wenzke M, Schwarz C, Richter O, Hauss J and Seissler J: Diabetes mellitus and islet cell specific autoimmunity as adverse effects of immunsuppressive therapy by FK506/tacrolimus. Exp Clin Endocrinol Diabetes 108: 347-352, 2000.

8. Heit JJ, Apelqvist AA, Gu X, Winslow MM, Neilson JR, Crabtree GR and Kim SK: Calcineurin/NFAT signalling regulates pancreatic beta-cell growth and function. Nature 443: 345-349, 2006

9. Hernández-Fisac I, Pizarro-Delgado J, Calle C, Marques M, Sánchez A, Barrientos A and Tamarit-Rodriguez J: Tacrolimus-induced diabetes in rats courses with suppressed insulin gene expression in pancreatic islets. Am J Transplant 7: 2455-2462, 2007

10. Rodriguez-Rodriguez AE, Triñanes J,PorriniE, Velázquez-Garcia S, Fumero C, Vega-Prieto MJ, Díez-Fuentes ML, Luis Lima S, Salido E and Torres A: Glucose homeostasis changes and pancreatic $\beta$-cell proliferation after switching to cyclosporin in tacrolimus-induced diabetes mellitus. Nefrologia 35: 264-272, 2015 (In English, Spanish).

11. Senior PA, Paty BW, Cockfield SM, Ryan EA and Shapiro AM: Proteinuria developing after clinical islet transplantation resolves with sirolimus withdrawal and increased tacrolimus dosing. Am J Transplant 5: 2318-2323, 2005.

12. Desai NM, Goss JA, Deng S, Wolf BA, Markmann E, Palanjian M, Shock AP, Feliciano S, Brunicardi FC, Barker CF, et al: Elevated portal vein drug levels of sirolimus and tacrolimus in islet transplant recipients: Local immunosuppression or islet toxicity? Transplantation 76: 1623-1625, 2003.

13. JahnI,Busch M,OttU,WolfG and BattefeldW: Posttransplantation diabetes mellitus in patients after kidney transplantation-Incidence and risk factors. Dtsch Med Wochenschr 141: e173-e182, 2016 (In German).

14. Liu JY, You RX, Guo M, Zeng L, Zhou P, Zhu L, Xu G, Li J and Liu D: Tacrolimus versus cyclosporine as primary immunosuppressant after renal transplantation: A meta-analysis and economics evaluation. Am J Ther 23: e810-e824, 2016.

15. Li Y, Goto T, Yamakuni K, Takahashi H, Takahashi N, Jheng HF, Nomura W, Taniguchi M, Baba K, Murakami S and Kawada T: 4-Hydroxyderricin, as a PPAR $\gamma$ agonist, promotes adipogenesis, adiponectin secretion, and glucose uptake in 3T3-L1 cells. Lipids 51: 787-795, 2016.

16. Voytovich MH, Simonsen C, Jenssen T, Hjelmesaeth J Asberg A and Hartmann A: Short-term treatment with rosiglitazone improves glucose tolerance, insulin sensitivity and endothelial function in renal transplant recipients. Nephrol Dial Transplant 20: 413-418, 2005

17. Isokuortti E, Zhou Y, Peltonen M, Bugianesi E, Clement K, Bonnefont-Rousselot D, Lacorte JM, Gastaldelli A, Schuppan D, Schattenberg JM, et al: Use of HOMA-IR to diagnose non-alcoholic fatty liver disease: A population-based and inter-laboratory study. Diabetologia 60: 1873-1882, 2017.

18. Bloom S, Ghatei M and Bech P: Measurement of gut hormones in plasma. Methods Mol Biol 1065: 147-170, 2013. 
19. Pichaiwong W, Hudkins KL, Wietecha T, Nguyen TQ, Tachaudomdach C, Li W, Askari B, Kobayashi T, O'Brien KD, Pippin JW, et al: Reversibility of structural and functional damage in a model of advanced diabetic nephropathy. J Am Soc Nephrol 24: 1088-1102, 2013.

20. Arocho A, Chen B, Ladanyi M and Pan Q: Validation of the 2-DeltaDeltaCt calculation as an alternate method of data analysis for quantitative PCR of BCR-ABL P210 transcripts. Diagn Mol Pathol 15: 56-61, 2006.

21. Park S, Kim DS and Kang S: Vitamin D deficiency impairs glucose-stimulated insulin secretion and increases insulin resistance by reducing PPAR- $\gamma$ expression in nonobese type 2 diabetic rats. J Nutr Biochem 27: 257-265, 2016.

22. Massaro M, Scoditti E, Pellegrino M, Carluccio MA, Calabriso N, Wabitsch M, Storelli C, Wright Mand De Caterina R: Therapeutic potential of the dual peroxisome proliferator activated receptor (PPAR) $\alpha / \gamma$ agonist aleglitazar in attenuating TNF- $\alpha$-mediated inflammation and insulin resistance in human adipocytes. Pharmacol Res 107: 125-136, 2016.

23. Dai C, Wang X, Wu Y, Xu Y, Zhuo S, Qi M, Ji W and Zhan L: Polarity protein AF6 controls hepatic glucose homeostasis and insulin sensitivity by modulating IRS1/AKT insulin pathway in a SHP2-dependent manner. Diabetes 68: 1577-1590, 2019.

24. Albaghdadi AJ, Hewitt MA, Putos SM, Wells M, Ozolinš TR and Kan FW: Tacrolimus in the prevention of adverse pregnancy outcomes and diabetes-associated embryopathies in obese and diabetic mice. J Transl Med 15: 32, 2017.

25. Gnatta D, Keitel E, Heineck I, Cardoso BD, Rodrigues AP, Michel K and Garcia VD: Use of tacrolimus and the development of posttransplant diabetes mellitus: A Brazilian single-center, observational study. Transplant Proc 42: 475-478, 2010.

26. Dabrowska-Zamojcin E, Tarnowski M, Szydlowski M, Romanowski M, Dziedziejko V, Safranow K, Domanski L and Pawlik A: KCNJ11 and KCNQ1 gene polymorphisms are not associated with post-transplant diabetes mellitus in kidney allograft recipients treated with tacrolimus. Folia Biol (Praha) 63: 115-119, 2017.

27. Torres A, Hernández D, Moreso F, Serón D, Burgos MD Pallardó LM, Kanter J, Díaz Corte C, Rodríguez M, Diaz JM, et al Randomized controlled trial assessing the impact of tacrolimus versus cyclosporine on the incidence of posttransplant diabetes mellitus. Kidney Int Rep 3: 1304-1315, 2018.

28. Jin J, Jin L, Luo K, Lim SW, Chung BH and Yang CW: Effect of empagliflozin on tacrolimus-induced pancreas islet dysfunction and renal injury. Am J Transplant 17: 2601-2616, 2017.

29. Gachon F, Loizides-Mangold U, Petrenko V and Dibner C: Glucose homeostasis: Regulation by peripheral circadian clocks in rodents and humans. Endocrinology 158: 1074-1084, 2017.

30. Duijnhoven EM, Boots JM, Christiaans MH, Wolffenbuttel BH and Van Hooff JP: Influence of tacrolimus on glucose metabolism before and after renal transplantation: A prospective study. J Am Society Nephrol 12: 583-588, 2001.

31. Terauchi Y and Kadowaki T: PPAR and diabetes. Nihon Rinsho 63: 623-629, 2005 (In Japanese).

32. Holguin F, Rojas M and Hart CM: The peroxisome proliferator activated receptor gamma (PPARgamma) ligand rosiglitazone modulates bronchoalveolar lavage levels of leptin, adiponectin, and inflammatory cytokines in lean and obese mice. Lung 185 367-372, 2007.

33. Azaïs H, Leroy A, Ghesquiere L, Deruelle P and Hanssens S Effects of adipokines and obesity on uterine contractility. Cytokine Growth Factor Rev 34: 59-66, 2017.

34. Jaganathan R, Ravindran R and Dhanasekaran S: Emerging role of adipocytokines in type 2 diabetes as mediators of insulin resistance and cardiovascular disease. Can J Diabetes 42: 446-456 e1, 2018.
35. Kurian B, Joshi R and Helmuth A: Effectiveness and long-term safety of thiazolidinediones and metformin in renal transplant recipients. Endocr Pract 14: 979-984, 2008

36. Villanueva $\mathrm{G}$ and Baldwin D: Rosiglitazone therapy of posttransplant diabetes mellitus. Transplantation 80: 1402-1405, 2005.

37. Gayet C, Leray V, Saito M, Siliart B and Nguyen P: The effects of obesity-associated insulin resistance on mRNA expression of peroxisome proliferator-activated receptor-gamma target genes, in dogs. Br J Nutr 98: 497-503, 2007.

38. Choi KC, Ryu OH, Lee KW, Kim HY, Seo JA, Kim SG, Kim NH, Choi DS, Baik SH and Choi KM: Effect of PPAR-alpha and -gamma agonist on the expression of visfatin, adiponectin, and TNF-alpha in visceral fat of OLETF rats. Biochem Biophys Res Commun 336: 747-753, 2005.

39. Blüher M and Paschke R: Analysis of the relationship between PPAR-gamma 2 gene variants and severe insulin resistance in obese patients with impaired glucose tolerance. Exp Clin Endocrinol Diabetes 111: 85-90, 2003.

40. Ruangkanchanasetr P, Sanohdontree N, Supaporn T, Sathavarodom N and Satirapoj B: Beta cell function and insulin resistance after conversion from tacrolimus twice-daily to extended-release tacrolimus once-daily in stable renal transplant recipients. Ann Transplant 21: 765-774, 2016.

41. Zhao J, Wang M, Deng W, Zhong D, Jiang Y, Liao Y, Chen B and Zhang X: ADP-ribosylation factor-like GTPase 15 enhances insulin-induced AKT phosphorylation in the IR/IRS1/AKT pathway by interacting with ASAP2 and regulating PDPK1 activity. Biochem Biophys Res Commun 486: 865-871, 2017.

42. Moon MK, Kang GH, Kim HH, Han SK, Koo YD, Cho SW, Kim YA, Oh BC, Park do J, Chung SS, et al: Thyroid-stimulating hormone improves insulin sensitivity in skeletal muscle cells via cAMP/PKA/CREB pathway-dependent upregulation of insulin receptor substrate-1 expression. Mol Cell Endocrinol 436: 50-58, 2016.

43. Cignarelli A, Genchi VA, Perrini S, Natalicchio A, Laviola L and Giorgino F. Insulin and insulin receptors in adipose tissue development. Int J Mol Sci 20: pii: E759, 2019.

44. Roncero I, Alvarez E, Acosta C, Sanz C, Barrio P, Hurtado-Carneiro V, Burks D and Blázquez E: Insulin-receptor substrate-2 (irs-2) is required for maintaining glucokinase and glucokinase regulatory protein expression in mouse liver. PLoS One 8: e58797, 2013.

45. Bendickova K, Tidu F and Fric J: Calcineurin-NFAT signalling in myeloid leucocytes: new prospects and pitfalls in immunosuppressive therapy. EMBO Mol Med 9: 990-999, 2017.

46. Mathis AS, Jin S, Friedman GS, Peng F, Carl SM and Knipp GT: The pharmacodynamic effects of sirolimus and sirolimus-calcineurin inhibitor combinations on macrophage scavenger and nuclear hormone receptors. J Pharm Sci 96: 209-222, 2007.

47. Aye IL, Gao X, Weintraub ST, Jansson T and Powell TL: Adiponectin inhibits insulin function in primary trophoblasts by PPAR $\alpha$-mediated ceramide synthesis. Mol Endocrinol 28: 512-524, 2014

48. Boerner BP, Shivaswamy V, Wolatz E and Larsen J: Post-transplant diabetes: Diagnosis and management. Minerva Endocrinol 43: 198-211, 2018.

49. Li Z, Sun F, Zhang Y, Chen H, He N, Chen H, Song P, Wang Y, Yan $S$ and Zheng S: Tacrolimus induces insulin resistance and increases the glucose absorption in the jejunum: A potential mechanism of the diabetogenic effects. PLoS One 10: e0143405, 2015. 